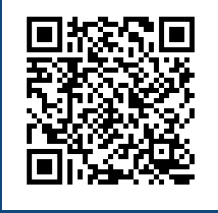

Keywords:

Hyperspectral

Leaf reflectance

Vegetation indices

Feature selection

Bootstrap

Historic:

Received 15/03/2019

Accepted 02/06/2019

Correspondence:

luizfelipe.florestal@gmail.com
Luiz Felipe Ramalho de Oliveiraa ${ }^{\mathrm{a}+}$, Reynaldo Campos Santana ${ }^{\mathrm{lb}}$, Marcio Leles Romarco de Oliveira'c

\section{NONDESTRUCTIVE ESTIMATION OF LEAF NUTRIENT CONCENTRATIONS IN EUCALYPTUS PLANTATIONS}

OLIVEIRA, L. F. R,; SANTANA, R. C.; OLIVEIRA, M. L. R. Nondestructive estimation of leaf nutrient concentrations in Eucalyptus plantations. CERNE, v. 25, n. 2, p. 184-194, 2019.

\section{HIGHLIGHTS}

Optimal wavelengths related to nutrient concentrations were identified.

Nutrient indices were developed to predict leaf nutrient concentrations.

Nutrient concentration in Eucalyptus were predicted by spectral indices.

Quantitative models between spectra and nutrient concentrations were established.

\section{ABSTRACT}

Determination of leaf nutrient concentrations is traditionally performed by carrying out destructive procedures, requiring laboratory chemical analysis, specialized equipment, and skilled labor. However, technological advances in recent years have now made it possible to analyze leaf nutrient concentrations using non-destructive methods such as leaf reflectance. This study evaluates the relationship between leaf reflectance and nutrient concentration in order to develop and apply nutrient indices by proximal sensing data in plantations of Eucalyptus. Two experiments were carried out for the development, application and validation of nutrient indices in Eucalyptus stands in the municipalities of Lassance and Três Marias, Minas Gerais state, Brazil. Study I was undertaken in Eucalyptus stands with 25 months old and, three clones. Leaves from the lower crown were visually classified into five color patterns using the Munsell chart for plant tissues. Study II was carried out in commercial stands of a hybrid of Eucalyptus urophylla ST Blake, whith 9, 12, 15 and 25 months old. Analysis revealed strong relationships between leaf nutrients and leaf reflectance in the visible and near infrared regions $(400-900 \mathrm{~nm})$ of the light spectrum. Correlation analysis between leaf reflectance and nutrients can be useful in an exploratory analysis of leaf nutrient concentration. Some nutrient indices developed ( NI, PI, SI and Cul) provided satisfactory estimates of leaf nutrient concentration in Eucalyptus stands. The nutrient indices developed in this study may be a useful alternative to laboratory chemical analysis. 


\section{INTRODUCTION}

Nutrient concentration in the tissues of a plant, especially foliage tissue, is directly related to exchange processes between matter and energy, including photosynthesis, evapotranspiration and respiration (Marschner, 1995). Consequently, evaluation of leaf nutrient concentrations (LNCs) is useful for understanding a plant's nutritional needs, planning fertilization, and optimizing the economic return from crops by maximizing productivity and minimizing resource inputs.

Determination of LNCs is traditionally performed using destructive procedures, requiring laboratory chemical analysis, specialized equipment, and skilled labor. However, technological advances in recent years have made it possible to analyze LNC using nondestructive methods (Pimstein et al., 20 I I; Mahajan et al., 2016; Oliveira et al., 2017). Spectral analysis techniques, using a variety of sensors, have enabled crops to be managed using non-destructive methods (Ustin et al., 2009; Ollinger, 20I0; Schlemmer et al., 20I3), and the technology could be extended to tree plantations (Stein et al., 20I4; Oliveira et al., 2017).

Remotely-sensed analysis techniques require multiple electromagnetic wavelengths reflected by the plant's foliage to be processed. The visible region (VIS, $400-700 \mathrm{~nm}$ ) is influenced mainly by leaf pigments, especially chlorophyll (Gitelson et al., 2003; 2006; 2009). The near infrared region (NIR, 70I - I200 nm) is related to morphological and anatomical leaf structures (Gates et al., 1965).

Currently, several indices are used to quantify the relationships between reflectance in the VIS and NIR regions and LNCs. However, such implementation has been limited to estimates of leaf pigments (eg, Gitelson et al., 2003; 2006; 2009) and nitrogen (N, eg Fitzgerald et al., 2010; Schlemmer et al., 2013; Oliveira et al., 2017). Deficiencies in nutrients other than $N$ can alter plant metabolism and consequently a leaf's reflectance (Mariotti et al., 1996; Mahajan et al., 20I4). However, applications linking leaf reflectance to other macronutrients and micronutrients are poorly developed for trees (eg, Ponzoni and Gonçalves, 1999; Adams et al., 2000; Pimstein et al., 20 I ; Mahajan et al., 2014; Stein et al., 2014). Therefore, the study of relationships between $\mathrm{N}$, phosphorous $(\mathrm{P})$, potassium $(\mathrm{K})$, calcium $(\mathrm{Ca})$, magnesium $(\mathrm{Mg})$, sulfur $(\mathrm{S})$, boron $(\mathrm{B})$, iron $(\mathrm{Fe})$, zinc $(\mathrm{Zn})$, manganese $(\mathrm{Mn})$ and cooper $(\mathrm{Cu})$ concentrations and leaf reflectance can be useful to procced nondestructive analysis in Eucalyptus stands.

The objective of this study is to predict LNCs using leaf reflectance in order to develop nutrient indices of Eucalyptus plantation by proximal sensing data.

\section{MATERIAL AND METHODS}

Two studies (Study I and Study II) were carried out for the development, application and validation of nutrient indices using Eucalyptus stands in the counties of Lassance and Três Marias, Minas Gerais - Brazil (Figure I).

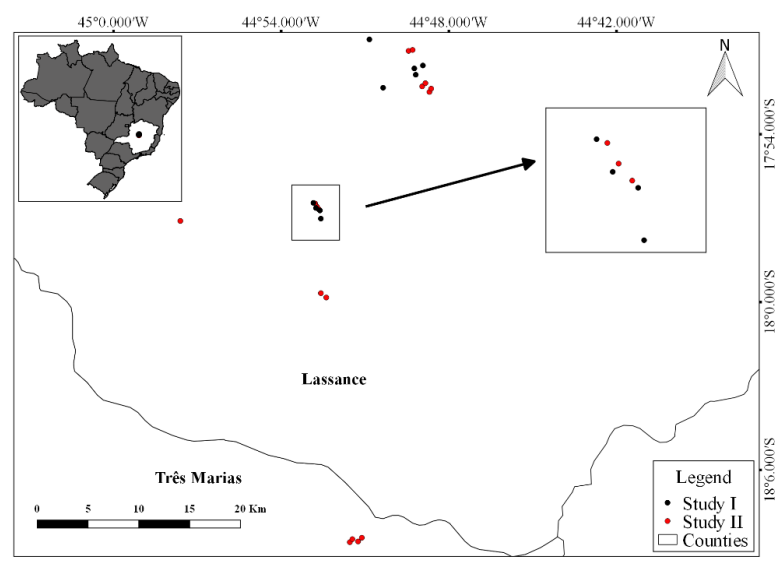

FIGURE I Study I and Study II plots.

Study I was established in Eucalyptus stands with 25 months old, planted with $7.0 \times 1.3 \mathrm{~m}$ tree spacing, with three clones (E. urophylla $\times E$. grandis: GG680, E. urophylla $x$ E. grandis: GG682 and hybrid of $E$. urophylla ST Blake: II44). In these stands nine plots of 10 ha were allocated, three per clone. Leaves from the lower parts of tree crowns were visually classified into five color patterns using the Munsell chart for plant tissues (Gretag-Macbeth, New Winsor, NY, USA). The leaf color patterns were defined by the clear expression of the biochemical cycling of nutrients (Table I).

TABLE I Leaf color patterns sampled in Eucalyptus stands.

\begin{tabular}{cccccc}
\hline $\begin{array}{c}\text { Color name } \\
\text { diagrams }\end{array}$ & $\begin{array}{c}\text { Matte color } \\
\text { chips }\end{array}$ & Hue & Value & Chroma & $\begin{array}{c}\text { Munsell } \\
\text { color code }\end{array}$ \\
\hline $\begin{array}{c}\text { Brilliant } \\
\text { yellow green }\end{array}$ & $7.5 \mathrm{GY}$ & 8 & 8 & $7.5 \mathrm{GY} 8 / 8$ \\
\hline $\begin{array}{c}\text { Light yellow } \\
\text { green }\end{array}$ & $7.5 \mathrm{GY}$ & 8 & 4 & $7.5 \mathrm{GY} 8 / 4$ \\
\hline Brown & $7.5 \mathrm{YR}$ & 4 & 2 & $7.5 \mathrm{YR} 4 / 2$ \\
\hline Yellow & $2.5 \mathrm{Y}$ & 7 & 6 & $2.5 \mathrm{Y} 7 / 6$ \\
\hline Strong yellow & & $2.5 \mathrm{Y}$ & 8 & 10 & $2.5 \mathrm{Y} 8 / 10$ \\
\hline
\end{tabular}

For each color pattern, 30 leaves were collected from each of the nine plots. A leaf was collected from each tree encountered on a random zig-zag walk. Each set of 30 leaves constituted a composite sample, and there was a total of 45 composite samples ( 3 clones $\times 3$ plots $x 5$ leaf color patterns). This sampling was performed to obtain a wide variation in LNCs. Immediately after 
leaf collection, the leaf reflectance $(400-900 \mathrm{~nm})$ was scanned in the abaxial part of each leaf, $10 \mathrm{~mm}$ from the lower border, on the left side of each leaf using a Cl-7IO mini-spectrometer (CID Bio- Science - Camas, Washington, USA).

The leaf reflectance was analyzed using SpectraSnap! (software version I.I.3.I50, CID BioScience) with 300 milliseconds of integration time, a boxcar with 10 points and two scans for averaging. Subsequently, the reflectance spectra were smoothed using the Savitsky-Golay algorithm (Savitzky and Golay, 1964) with a second-degree polynomial model. From every set of 30 smoothed spectra per composite sample, the average value of leaf reflectance was obtained, giving values for each of the 45 composite samples.

Subsequent to collecting the leaf reflectance, the 30 leaves for each composite sample were placed in paper bags and oven-dried with forced air circulation at $65^{\circ} \mathrm{C}$. After drying, the 45 composite samples were digested in nitro-perchloric solution and the concentrations of $\mathrm{Ca}, \mathrm{Mg}, \mathrm{S}, \mathrm{Zn}, \mathrm{Fe}$ and $\mathrm{Mn}$ were determined by spectrophotometry. The $\mathrm{P}$ concentration was determined by colorimetry, the $\mathrm{K}$ concentration by flame photometry and the total $\mathrm{N}$ concentration using the Kjeldahl method following sulfuric digestion.

Study II was carried out in commercial stands of the hybrid of Eucalyptus urophylla ST Blake (clone II44), which were 9, 12, 15 and 25 months old. Sixteen plots of 10 ha were allocated, four for each age of tree (Figure I). Leaves from 25 trees in each of these plots were sampled; they were taken from the upper canopies of the stands ( $80 \%$ percentile). For each tree, four completely expanded leaves, without physical damage, were collected at the four cardinal points near the middle of each Eucalyptus crown (Bellote and Silva, 2000). The 100-leaf set was made up of a composite sample used to determine nutrients and to collected leaf reflectance. The procedures for collecting, smoothing the reflectance spectra and leaf chemical analysis were the same as those used in Study I.

The results obtained from Studies I and II were grouped into a unique dataset and split into two groups: $75 \%$ as a training set and $25 \%$ as a validation set using the bootstrap resampling method with 1000 random iterations (Efron and Tibshirani, 1994). The bootstrap statistic involves randomly composing the population samples $n$ times, producing $n$ statistical values with the objective of reducing the error associated with nonrepresentative samples. The training set was used to generate the models for LNCs, while the validation set was used to validate the regression model generated.
The smoothed leaf reflectance spectra and the nutrient concentrations in the training set for the same composite sample were correlated in each iteration. This procedure was carried out to verify the effect of nutrients on Eucalyptus leaf by reflectance spectral responses. The Pearson correlation $(r)$ was obtained using two vectors in each iteration: the corresponding average smoothed leaf reflectance of the training set and the foliar chemical analysis of the same samples. In order to identify significant wavelengths, a p-value $(\alpha<0.05)$ was also computed.

Spectral indices for different nutrients were calculated with all possible combinations of leaf reflectance at wavelengths between 400 and $900 \mathrm{~nm}$. The indices were developed based on the Normalized Difference Vegetation Index (NDVI) model (Equation I), wherein: NDVI is nutrient index based on Normalized Difference Vegetation Index; is the reflectance at wavelength $(\lambda) x$ and is the reflectance at wavelength $(\lambda)$ $y$, with $x$ and $y$ varying from 400 to $900 \mathrm{~nm}$.

$\operatorname{NDVI}=\frac{\left(\rho_{\lambda x}-\rho_{\lambda y}\right)}{\left(\rho_{\lambda x}+\rho_{\lambda y}\right)}$

The nutrient indices were evaluated based on the mean for the coefficient of determination $\left(R^{2}\right.$ train $)$ in all iterations, obtained by simple linear regressions. The $R_{\text {train }}^{2}$ mean values were organized into matrices ranging from white, for smaller $R_{\text {train }}^{2}$, up to black, for larger $R^{2}{ }_{\text {train }}$. Among all the indices, the one that provided the highest $R_{\text {train }}^{2}$ value in each nutrient was selected for analysis of the regression and application in the validation set. The analysis of the quality of the adjustments was made based on the mean of the Root of Mean Square Error $\left(R M S E_{\text {train }}\right)$ (Equation 2), wherein: $Y i$ is the nutrient concentration of sample $i$ estimated using the equation; $y i$ is the nutrient concentration observed in the laboratory of sample $i$; and $n$ is the total number of samples. RMSE $E_{\text {train }}: \mathrm{g} \mathrm{kg}^{-1}$ for $\mathrm{N}, \mathrm{P}, \mathrm{K}, \mathrm{Ca}, \mathrm{Mg}$ and S; $\mathrm{mg} \cdot \mathrm{kg}^{-1}$ for B, Zn, Mn, Fe and $\mathrm{Cu}$.

$\mathrm{RMSE}_{\text {train }}=\sqrt{\frac{\sum_{\mathrm{i}=1}^{\mathrm{n}}(\mathrm{Yi}-\mathrm{yi})^{2}}{\mathrm{n}}}$

To validate the nutrient indices and equations obtained for the training set, the determination coefficient $\left(R^{2}{ }_{v a l}\right)$ and the Root Mean of Square Error $\left(R M S E_{v a l}\right)$ were used; they were calculated in the same way as $R M S E_{\text {train }}$ (Equation 2). The Kernel density was used with the bandwidths chosen according to Silverman's rule of thumb (Silverman, 1986) to demonstrate the density 
of the statistics bootstraps in the training and validation sets. The mean of the parameters slope and intercept was used to estimate the concentration of each nutrient in the original dataset. All statistical procedures were carried out using the software R Core Team (2017) version 3.4.0, platform support $R$ Studio version I.0.I43.

Moreover, in order to aid the interpretation of the results obtained, mean and standard deviations of LNCs from commercial eucalyptus stands, which were between 0.4 and 7.0 years old, were used for reference (Galdino, 2015). These values came from an evaluation of 9608 leaf samples taken from the middle of each Eucalyptus crown, using the same method of leaf analysis as Studies I and II in this research.

\section{RESULTS}

The reflectance spectra in the bootstrap training and validation sets were similar (Figure 2). The visible spectrum, more specifically between $530-780 \mathrm{~nm}$, was the region of the reflectance spectrum within the samples.
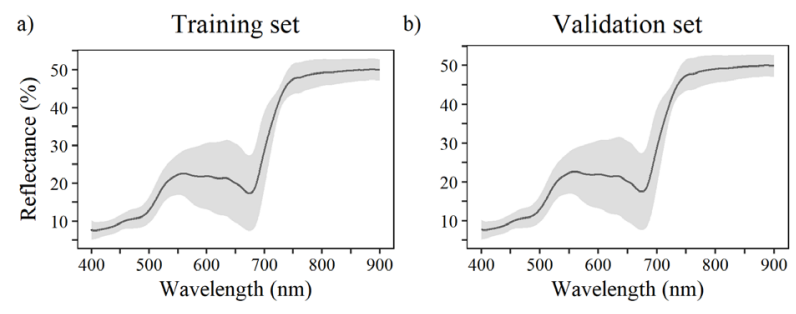

$\square$ Standard deviation $\square$ Mean

FIGURE 2 Reflectance spectrum of training and validation sets.

The samples provided a wide range of nutrient concentrations (Figure 3). This amplitude is desirable for the training and validation models. Nutrients with higher mobility, such as $\mathrm{N}$ and $\mathrm{P}$ presented lower concentrations when compared to the standard nutrient concentrations for Eucalyptus. The opposite was observed for some nutrients with lower mobility in plants, such as $\mathrm{Ca}, \mathrm{B}$ and Mn concentrations. The other nutrients concentrations were similar in the training/validation sets compared with standard nutrient concentration.

As can be observed in Figure 4, there was a negative correlation between N, P, K, S, Cu concentrations and leaf reflectance in almost the entire visible region (400 - $700 \mathrm{~nm}$ ). However, for $\mathrm{K}$ concentration, lower correlations were obtained in this region. The opposite was observed for $\mathrm{Ca}, \mathrm{B}$ and $\mathrm{Mn}$ concentrations, which showed positive correlations in almost the entire visible region. Furthermore, Fe concentration showed significant correlation only at wavelengths of $560-710$ $\mathrm{nm}$, and $\mathrm{Zn}$ concentration showed significant correlation only in a small region around the wavelength of 400 $\mathrm{nm}$. There was no significative correlation between $\mathrm{Mg}$ concentration and leaf reflectance for any of the wavelengths studied.

The correlation curves between $\mathrm{N}, \mathrm{P}, \mathrm{S}, \mathrm{Cu}, \mathrm{K}$ concentrations and leaf reflectance followed a similar pattern for all wavelengths evaluated (Figure 4). Moreover, the correlation curves between $\mathrm{Ca}, \mathrm{Mn}, \mathrm{B}$ concentrations and leaf reflectance also showed a similar pattern. Additionally, around a wavelength of $730 \mathrm{~nm}$ all nutrients presented correlations with the leaf reflectance close to zero. Above this wavelength, all nutrients reversed their relationship with leaf reflectance. Most of the nutrient concentrations exhibited maximum correlations in the red edge region (680 - $740 \mathrm{~nm}$ ); only $\mathrm{Zn}$ demonstrated a maximum correlation in the region of blue $(400-450 \mathrm{~nm})$ and $\mathrm{Ca}$ at around $750 \mathrm{~nm}$.

For most nutrients, the wavelengths combinations in red edge region provided high $R^{2}$ values in the development of the index (Figure 5). All indices developed showed significant $R^{2}$ at $95 \%$ probability using $\mathrm{t}$ test $(\alpha<$ $0.05)$. The Nitrogen Index (NI) had the highest $R^{2}(0.96)$, followed by the Phosphorus Index $\left(\mathrm{PI}, R^{2}=0.92\right)$, Sulfur Index $\left(\mathrm{SI}, R^{2}=0.79\right)$, Copper Index (Cul, $\left.R^{2}=0.7 \mathrm{I}\right)$, Potassium Index $\left(\mathrm{KI}, R^{2}=0.64\right)$, Calcium Index (Cal, $R^{2}$ $=0.60)$, Manganese Index $\left(\mathrm{Mnl}, R^{2}=0.56\right)$, Boron Index $\left(\mathrm{BI}, R^{2}=0.55\right)$, Zinc Index $\left(\mathrm{Znl}, R^{2}=0.36\right)$, Iron Index $\left(\mathrm{Fel}, R^{2}=0.22\right)$ and Magnesium Index (Mgl, $\left.R^{2}=0.17\right)$.

The $\mathrm{Nl}$ obtained the highest $R^{2}$ values followed by others with wavelength combinations in the red edge region (Figure 5). To estimate the $\mathrm{P}$ concentration, two well-demarcated regions of high $R^{2}$ were obtained, one in the red edge region and other in the green region $(\approx 560$ - $570 \mathrm{~nm}$ ). However, the highest $R^{2}$ value was obtained in the red edge region. Therefore, the PI was developed with wavelengths in this region. Similar to $\mathrm{PI}$, other indices like $\mathrm{KI}, \mathrm{Cal}, \mathrm{SI}$ and $\mathrm{Mnl}$ obtained their maximum $R^{2}$ values in more than one region of spectrum. For $\mathrm{KI}$, the maximum was obtained in the green wavelength region; for $\mathrm{Cal}$ and $\mathrm{SI}$ maximums were in wavelength combinations in red edge region, and the Mnl used red edge and blue wavelength regions. $\mathrm{Mnl}$ and $\mathrm{Cul}$ were indices formed by combinations of distinct regions of the electromagnetic spectrum with the Cul developed using blue and green wavelengths. Some indices obtained higher values of $R^{2}$ with combinations of wavelengths in the blue region, such as $\mathrm{Znl}$ and Fel. Additionally, $\mathrm{Mgl}$ obtained higher $R^{2}$ values using near infrared (NIR) wavelengths. Nevertheless, $\mathrm{Mgl}$ was the index with the lowest $R^{2}$. 

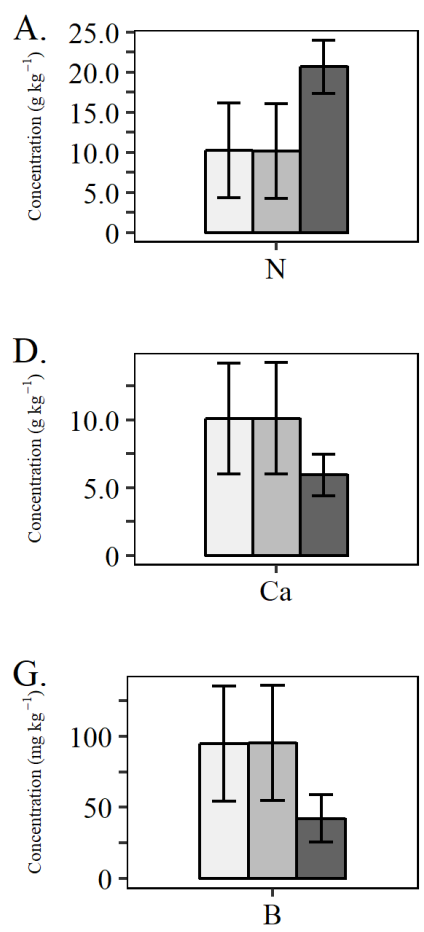

$\mathrm{H}$.

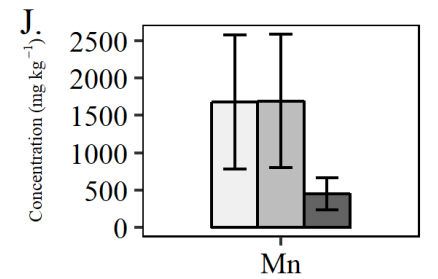

B.
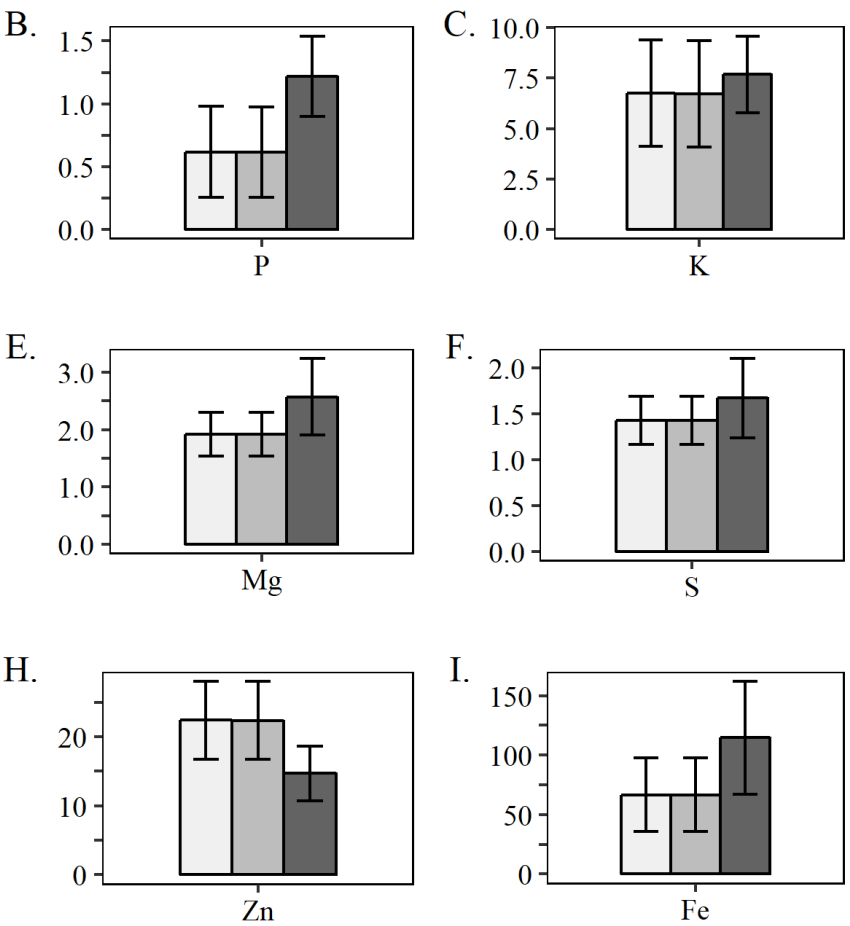

I.

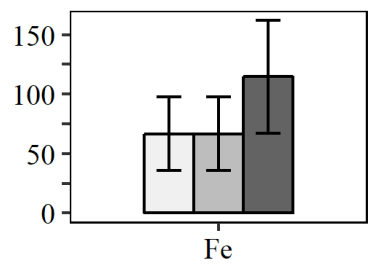

K.

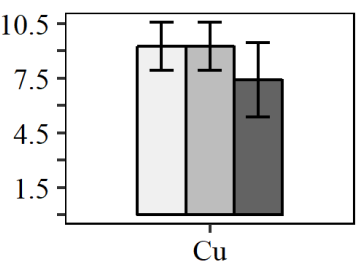

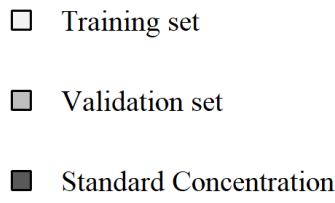

FIGURE 3 Mean and standard deviation of nutrient concentrations in training and validation sets and standard concentrations to Eucalyptus. Standard concentration data from Galdino (2015).

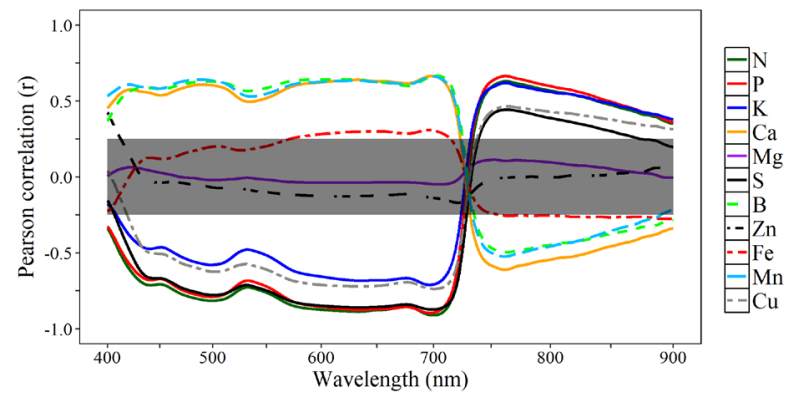

FIGURE 4 Pearson correlation ( $r$ ) between nutrient concentrations and leaves reflectance from training set. Shaded region illustrate significance level $(\alpha<0.05)$.

To demonstrate all iterations for the bootstrap regression, training and validating were used to produce the Kernel density plot for each leaf nutrient (Figure 6). The estimates of N, P, S and Cu concentrations using their related indices gave higher $R_{\text {train }}^{2}$ and $R_{\text {val }}^{2}$, on average. The estimate for nitrogen using the $\mathrm{NI}$ gave the highest $R^{2}{ }_{\text {train }}$ and $R_{\text {val }}^{2} 0.96$, on average. Moreover, the $\mathrm{NI}$ estimates $\mathrm{N}$ with $R M S E_{\text {train }}=1.23\left(\mathrm{~g}^{\mathrm{kg}} \mathrm{kg}^{-1}\right)$ and $R M S E_{\mathrm{val}}=1.20\left(\mathrm{~g} \cdot \mathrm{kg}^{-1}\right)$, on average. As can be observed in Figure 7, this index showed excellent prediction of $\mathrm{N}$ concentration.

Similar to predicted $\mathrm{N}$ concentration, the $\mathrm{PI}$ estimate for the $\mathrm{P}$ concentration with $R_{\text {train }}^{2}=0.92, R_{\text {val }}^{2}=$ 0.93, $R M S E_{\text {train }}=0.10\left(\mathrm{~g} \mathrm{~kg}^{-1}\right)$ and $R M S E_{\mathrm{val}}=0.09\left(\mathrm{~g} \mathrm{~kg}^{-1}\right)$ on average (Figure 6), resulted in an excellent prediction of $\mathrm{P}$ concentration (Figure 7). The $\mathrm{SI}$ and Cul estimates for the $\mathrm{S}$ and $\mathrm{Cu}$ concentrations showed relationships $R_{\text {train }}^{2}=0.79, R_{\text {val }}^{2}=0.80$ and $R_{\text {train }}^{2}=0.7 \mathrm{I}, R_{\text {val }}^{2}=0.70$ respectively, on average (Figure 6). Furthermore, the SI provided $R M S E_{\text {train }}$ and $R M S E_{\text {val }}=0.12 \mathrm{~g} \cdot \mathrm{kg}^{-1}$ and $\mathrm{Cul}$ provided $R M S E_{\text {train }}$ and $R M S E_{\text {val }}=0.7 \mathrm{I} \mathrm{mg} \cdot \mathrm{kg}^{-1}$ on average (Figure 6), resulting in good predictions for both $S$ concentration and $\mathrm{Cu}$ concentration (Figure 7).

The linear relationships between $\mathrm{K}, \mathrm{Ca}, \mathrm{B}$ and $\mathrm{Mn}$ concentrations and their indices were less precise than previous nutrients (Figures 6, 7). However, these nutrients were predicted with $R_{\text {train }}^{2}$ and $R_{\text {val }}^{2}$ average ranges between 0.55 and 0.66 . Moreover; the $R M S E_{\text {train }}$ and $R M S E_{\text {val }}$ on average were 1.56 and $1.57 \mathrm{~g} \mathrm{~kg}^{-1}$ for $\mathrm{K}$ 

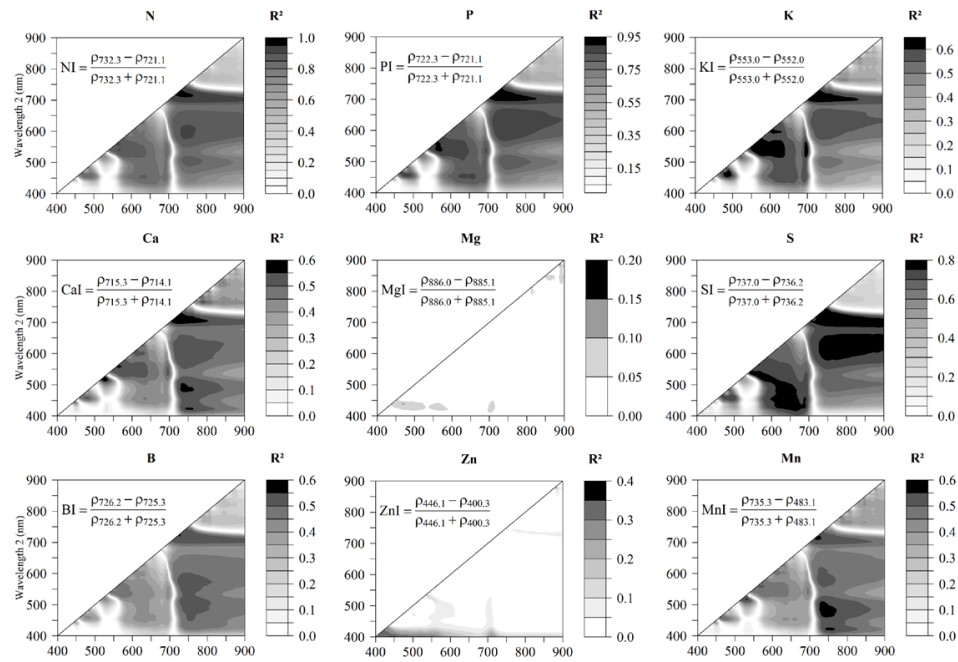

$\mathrm{Zn}$
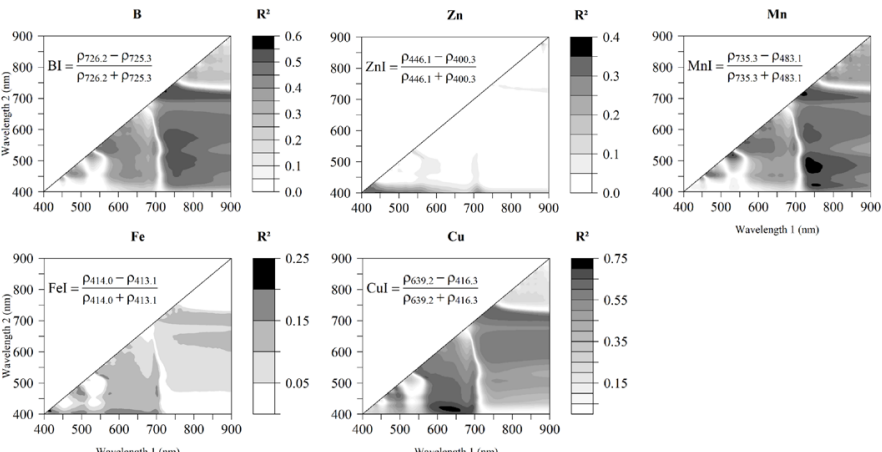

FIGURE 5 Determination coefficient $\left(R^{2}\right)$ between indices and nutrient concentrations from training set. $\mathrm{NI}=$ Nitrogen $\mathrm{Index} ; \mathrm{Pl}=$ Phosphorus Index, $\mathrm{Kl}=$ Potassium Index; $\mathrm{Cal}=$ Calcium Index; $\mathrm{MgI}=$ Magnesium Index; $\mathrm{SI}=$ Sulphur Index; $\mathrm{Bl}=$ Boron Index; $\mathrm{ZnI}=$ Zinc Index; $\mathrm{Mnl}=$ Manganese Index; Fel = Iron Index; Cul= Copper Index.

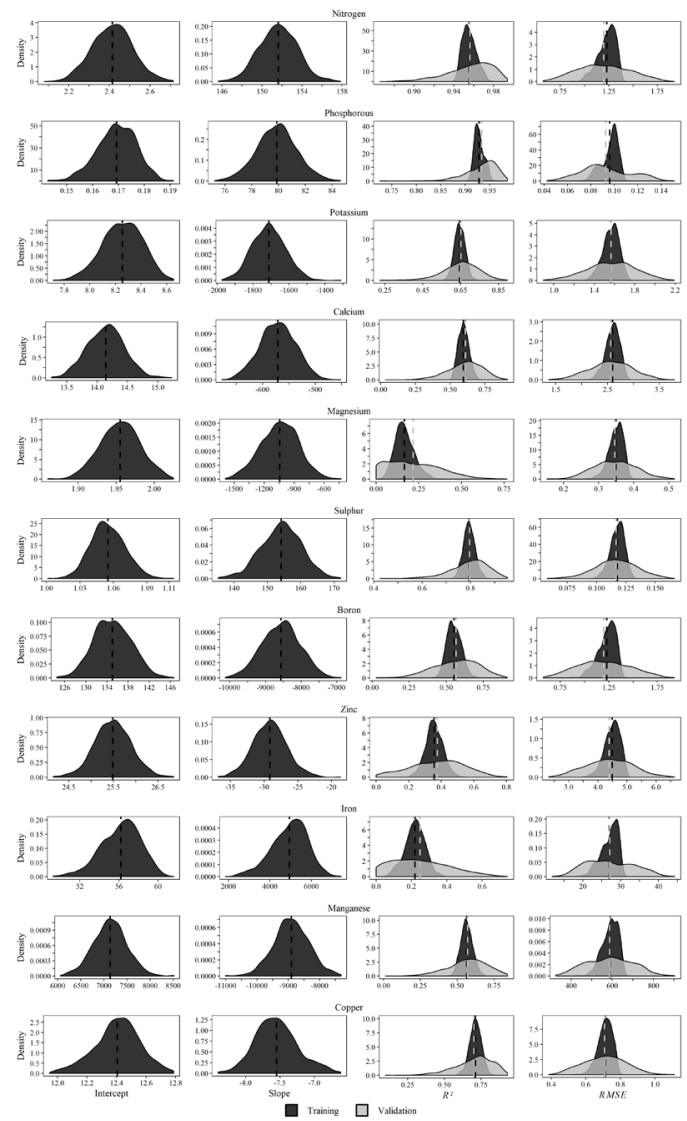

FIGURE 6 Kernel Density of parameters intercept and slope, R2train, R²val, RMSEtrain and RMSEval. Training average: black dotted vertical lines. Validation average: grey dotted vertical lines. 

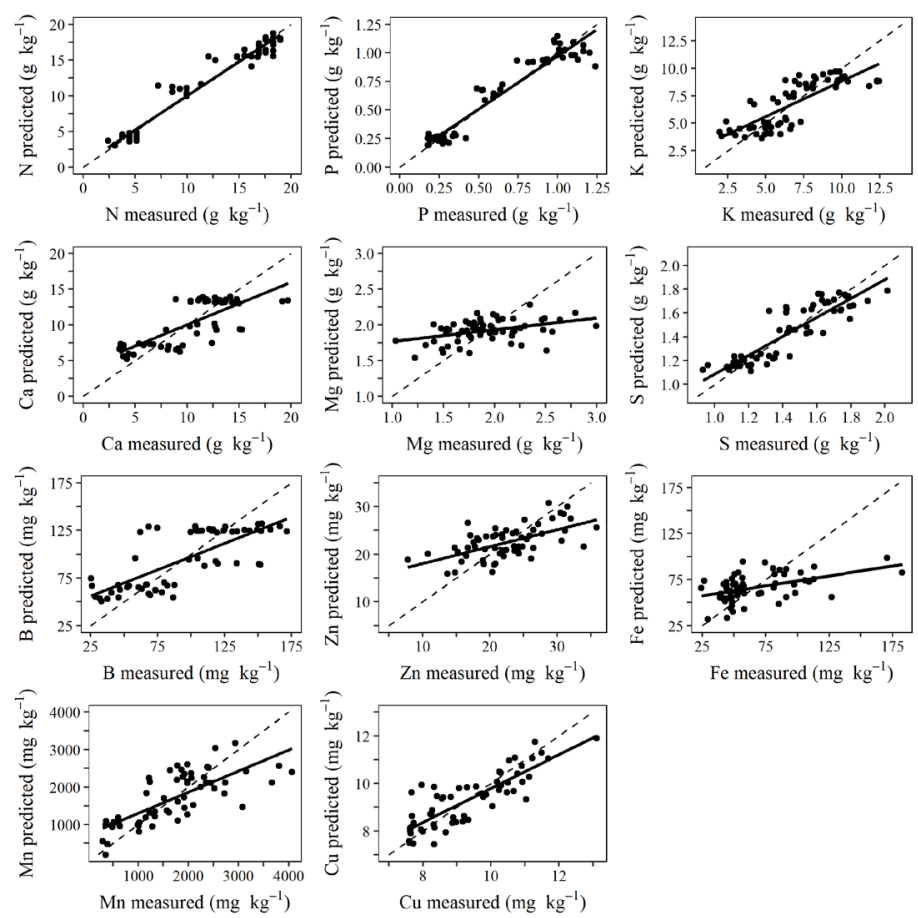

Fe measured $\left(\mathrm{mg} \mathrm{kg}^{-1}\right)$

FIGURE 7 Measured and predicted nutrient using nutrient indices.

concentration, 2.60 and $2.56 \mathrm{~g} \cdot \mathrm{kg}^{-1}$ for Ca concentration, 26.72 and $26.46 \mathrm{mg} \cdot \mathrm{kg}^{-1}$ for $B$ concentration and 589.83 and $587.32 \mathrm{mg} \cdot \mathrm{kg}^{-1}$ for Mn concentration (Figure 6).

On average, the estimates for $\mathrm{Mg}, \mathrm{Zn}$ and $\mathrm{Fe}$ concentrations and their related indices showed the lowest linear relationships (Figure 7). The $\mathrm{Mgl}$ was the index with the lowest $R_{\text {train }}^{2}(0.17)$ and $R_{\text {val }}^{2}(0.22)$, and it also had the peak $R_{\text {val }}^{2}$ for Kernel density, at close to 0 (Figure 6). Likewise, the Fel also had a peak $R_{\text {val }}^{2}$ for Kernel density close to zero and the average linear relationship with Fe concentration was 0.22 for training and 0.25 for validation. The $\mathrm{Znl}$ provided an $R_{\text {val }}^{2}$ for Kernel density with a range of 0.00 to 0.80 , which may mean that the linear model is not suitable for estimating Zn concentration (Figure 6).

\section{DISCUSSION}

The major standard deviation range in the visible region is due to the color pattern used in leaf sampling (Table I). Changes in leaf color result in changes in leaf reflectance, mainly in the visible region (Merzlyak et al., 2003). The similarity between training and validation sets occurred as a result of using the bootstrap technique (Figures 2, 3). This is mainly because the bootstrap statistic distribution is based on a large number of resamples, representing the distribution for each statistic, based on a large number of samples (Efron and Tibshirani, 1994).
The negative correlation between N, P, K, Cu, S concentrations and foliar reflectance in the VIS region indicates that the lower these nutrients concentrations in the leaves, the higher will be the reflectance in this region (Figures 3 and 4). This similarity in pattern suggests that the nutrients in question are strongly correlated (Pimstein et al., 20II; Mahajan et al., 20l4). The increase of reflectance in the VIS region is mainly due to a reduction in chlorophyll concentration, triggered by the lowering of these nutrient concentrations (Al-Abbas et al., 1974; Adams et al., 2000). Consequently, with an increase of reflectance in the visible region there is a decrease in the intensity of the leaf color (Ponzoni and Gonçalves, 1999; Ayala-Silva and Beyl, 2005; Oliveira et al., 20I7). Thus, the reduction of the intensity of the green coloration of Eucalyptus leaves can be verified through a deficiency in these nutrients with evolution of the characteristic symptoms for each nutrient (Dell, 1996).

Regarding the $\mathrm{Ca}, \mathrm{B}$ and $\mathrm{Mn}$ concentrations, positive correlations obtained with leaf reflectance in the VIS region indicate that the higher their concentrations, the greater will be the leaf reflectance in this region (Figure 4). The concentrations of these nutrients are higher than the ranges for leaf desire concentrations for Eucalyptus (Figure 3). Therefore, an increase in these nutrient concentrations in leaves could indicate damage to the metabolism and a consequent increase in leaf reflectance as suggested by the correlations in the visible region (Figure 4). 
At around $700 \mathrm{~nm}$, correlation peaks were found for all nutrient concentrations (Figure 4). This region of the electromagnetic spectrum is widely used in the estimation of chlorophyll (Ustin et al., 2009) and strongly correlates with LNCs (Mutanga et al., 2004; Mahajan et al., 2014; Stein et al., 20I4). Thus, in the development of nutrient indices, the selection of at least one wavelength in this region was expected (Figure 4).

In the development of the $\mathrm{NI}$, combinations of wavelengths with high $R^{2}$ were obtained (Figure 5). The relationship between $\mathrm{N}$ and leaf reflectance is very strong in practically all VIS region (Figure 4). Therefore, in the literature, indices are able to estimate the $\mathrm{N}$ concentration in the blue wavelength region (Hansen and Schjoerring, 2002) and in the green, red and red edge regions (Oliveira et al., 20I7). In this study, better results were found using combinations of red edge wavelength regions (Figure 5 ). In addition, it is a common observation in plants that the $\mathrm{N}$ concentration estimates are the most accurate out of all leaf nutrients (Ponzoni and Gonçalves, 1999; Richardson and Reeves III, 2005; Mahajan et al., 2014). This was also the case in our study, where the $\mathrm{N}$ concentration was predicted with $R_{\text {train }}$ and $R_{v a l}$ above 0.95 (Figures 6 and 7).

Similar to the $\mathrm{NI}$, the PI was developed using a combination of red edge wavelengths (Figure 5). Moreover, combinations of leaf reflectance in the region for green wavelengths $(\approx 550 \mathrm{~nm})$ also showed high $R^{2}$ in the estimation of $\mathrm{P}$ concentration (Figure 5). Leaf reflectance in these regions of the electromagnetic spectrum is widely used to construct relationships between $\mathrm{P}$ concentration and leaf reflectance. For instance, leaf reflectance in the green region was related to $\mathrm{P}$ concentration in soybean plants (Glycine max (L.) Merr.) and seedlings of Eucalyptus saligna Smith (Milton et al., 199I; Ponzoni and Gonçalves, 1999). Nevertheless, correlation peaks between $P$ concentration and leaf reflectance in the green and red regions were also verified in sequoias (Gong et al., 2002). In addition, the region of red wavelengths has been used to estimate $P$ concentration in rangeland plants and pastures (Kawamura et al., 20II; Özyiğit and Bilgen, 20I3). It is assumed that for $\mathrm{P}$ concentration, there is the possibility of developing a PI in both regions, green and red edge. However, the adjustment performed with the PI in the red edge region presented a better estimate of $P$ concentration in this study (Figures 6, 7).

The correlations curve and matrix between $S$ concentration and leaf reflectance demonstrated a great similarity with the correlation curves between $\mathrm{N}$ and $\mathrm{P}$ concentrations and leaf reflectance (Figures 4 , 5). Moreover, the $S$ concentration predicted provided average $R_{\text {train }}$ and $R_{\text {val }}$ above 0.79 and $R M S E_{\text {train }}$ and $R M S E_{\text {val }}$ below $0.12 \mathrm{~g} \mathrm{~kg}^{-1}$ (Figures 6,7 ). The wavelengths selected for the SI were close to those selected for the NI (Figure 5). Probably, this was due to the high correlation between these nutrients, both of which have structural functions in amino acids and proteins (Marschner, 1995). The Cul, another index that predicted nutrient concentration with high accuracy (Figures 6, 7), was developed by combining blue and red wavelength regions (Figure 5). More than half of the $\mathrm{Cu}$ located in the chloroplast is in plastocyanin, a blue protein component of the electron transport chain (Marschner, 1995). Possibly because of this, these wavelengths provided the best results. Furthermore, Wang et al. (20I5) noted the red and red edge wavelength regions were strongly correlated with Cu concentration in Carex cinerascens Kük..

The $\mathrm{K}, \mathrm{Ca}, \mathrm{B}$ and $\mathrm{Mn}$ concentrations were predicted with less accuracy than the previously mentioned nutrients. The index constructed to predict $\mathrm{K}$ concentration $(\mathrm{KI})$ was developed by combining green wavelengths (Figure 5). Although the relationship between leaf reflectance and $K$ concentration was lower than for $\mathrm{N}$ and $\mathrm{P}$ concentrations (Figure 4), wavelength combinations in the visible region can be used to predict $\mathrm{K}$ concentration (Figure 5). Perhaps for this reason, the visible region has been used to detect $K$ deficiencies in Eucalyptus saligna Smith seedling leaves (Ponzoni and Gonçalves, 2010).

The Cal was developed using red edge wavelengths (Figure 5), a region that has a strong relationship with the metabolic changes in plants (Horler et al., 1983). Nevertheless, it was expected that the Cal would be developed using wavelengths related to foliar structural components such as the NIR region (Gates et al., 1965), because of Ca's structural function in the leaf cell wall (Marschner, 1995). However, there is evidence of the direct role of $\mathrm{Ca}$ in photosynthesis as a cofactor in photosystem II (Siegbahn and Crabtree, 1999), which would explain the selection of wavelengths in this region.

Another index for which a combination of red edge wavelengths provided better results was the $\mathrm{BI}$ (Figure 5). It was also expected that estimation for this nutrient concentration would be most accurate in the NIR wavelength region. This is mainly owing to B's contribution to cell wall biosynthesis and structure; it is the main element responsible for membrane integrity (Marschner, 1995). However, there is evidence that a cascade effect for this nutrient occurs, wherein changes in 
membrane integrity lead to changes in plant metabolism (Marschner, 1995). Probably due to this cascade effect, better results were obtained in the red edge wavelength region (Figure 5).

The Mnl was developed using red edge and blue wavelength regions (Figure 5). The red edge wavelengths, as previously stated, are related to the metabolism of plants (Horler et al., 1983). In terms of the choice of the blue wavelength region, the light in the blue region may cause a photodamage process to photosystem II. It is suggested that this process occurs at the manganese cluster of the oxygen-evolving complex (OEC) by means of photoexcitation of manganese (Hakala et al. 2005). It may be due to this that combinations of blue regions with high $R^{2}$ (Figure 5 ) can be observed. The $\mathrm{Mn}$ was predicted with mean values for $R_{\text {train }}^{2}$ and $R_{\text {val }}^{2}$ above 0.56 , and $R M S E_{\text {train }}$ and $R M S E_{\text {val }}$ below 590 $\mathrm{mg} \cdot \mathrm{kg}^{-1}$ (Figures 6, 7). As in this study, Adams et al. (2000), using NDVI to discriminate some micronutrient deficits in soybean leaves, obtained better results for $\mathrm{Mn}$ and $\mathrm{Cu}$ concentrations.

The $\mathrm{Znl}$, Fel and Mgl each provided lower linear relationships with their concentrations (Figure 6). Among these indices, a better estimate for $\mathrm{Zn}$ concentration was observed (Figures 6, 7). For the Fel, the green wavelength region $(\approx 550 \mathrm{~nm}$ ) estimated the Fe concentration better than the blue region in sunflowers (Helianthus annuus L.) and maize (Zea mays L.) (Mariotti et al., 1996). On the other hand, Adams et al. (2000), using NDVI, failed to discern $\mathrm{Fe}$ and $\mathrm{Zn}$ deficits in soybean leaves, in spite of obtaining better results for $\mathrm{Mn}$ and $\mathrm{Cu}$ concentrations. The Mgl was developed in the NIR wavelength region in this study. The Mgl was the index that presented smaller $R^{2}$ (Figure 5). Mostly, estimates of this nutrient provide lower $R^{2}$ of LNCs (Richardson and Reeves III, 2005; Stein et al., 20I4). Mg is the central atom of the chlorophyll molecule, in addition to being an activator of some enzymes in plants (Marschner, 1995). Thus, wavelengths more related to chlorophyll, such as the red edge region, were expected to be selected. However, the NIR region is generally used to estimate $\mathrm{Mg}$ concentration (Ferwerda and Skidmore, 2007; Mutanga et al., 2004).

\section{CONCLUSION}

There are strong relationships between leaf nutrients and leaf reflectance in the visible and near infrared regions $(400-900 \mathrm{~nm})$ of the spectrum. Correlation analysis between foliar reflectance and leaf nutrients may be useful in an exploratory analysis of LNCs. Some of the nutrient indices developed provided satisfactory estimates of LNC in Eucalyptus stands. The nutrient indices developed may offer a viable alternative to laboratory chemical analysis.

\section{REFERENCES}

ADAMS, M. L.; NORVELL, W. A.; PHILPOT, W. D.; PEVERLY, J. H. Toward the discrimination of manganese, zinc, copper, and iron deficiency in "Bragg" sobyan using spectral detection methods. Agronomy Journal, v. 92, p. 268-274, 2000.

AL-ABBAS, A. H.; BARR, R.; HALL, J. D.; CRANE, F. L.; BAUMGARDNER, M. F. Spectral of normal and nutrientdeficient maize leaves. Agronomy Journal, v. 66, n. I, p. 16-20, 1974.

AYALA-SILVA, T.; BEYL, C.A. Changes in spectral reflectance of wheat leaves in response to specific macronutrient deficiency. Advances in Space Research, v. 35, p. 305$317,2005$.

BELLOTE, A. F. J.; SILVA, H. D. Técnicas de amostragem e avaliações nutricionais em plantios de Eucalyptus spp. In: GONÇALVES, J. L. M., BENEDETTI, V., eds. Nutrição e fertilização florestal, IPEF, Piracicaba, Brasil, 2000. p. I05-I 34.

DELL, B. Diagnosis of nutrient deficiencies in eucalypts. In: ATTIWILL, P. M.; ADAMS, M.A., editors. Nutrition of eucalypts. Australia:CSIRO, 1996. p. 4I7-440.

EFRON, B.; TIBSHIRANI, R. J. An introduction to the bootstrap. Boca Raton:Chapman \& Hall, 1994. 430 p.

FERWERDA, J. G.; SKIDMORE, A. K. Can nutrient status of four woody plant species be predicted using field spectrometry? ISPRS Journal of Photogrammetry and Remote Sensing, v. 62, p. 406-4I4, 2007.

FITZGERALD, G.; RODRIGUEZ, D.; O'LEARY, G. Measuring and predicting canopy nitrogen nutrition in wheat using a spectral index - The canopy chlorophyll concentration index (CCCl). Field Crops Research, v. I I6, p. 3I8-324, 2010.

GATES, D. M.; KEEGAN, H. J.; SCHLETER, J. C.; WEIDNER, V. R. Spectral properties of plants. Applied Optics, v. 4, n. I, p. II-20, 1965.

GALDINO, M. P. Valores de referência e faixas de suficiência nutricional para avaliação do estado nutricional da cultura do eucalipto no Brasil. 20I5. 79 p. PhD thesis Universidade Federal de Viçosa, Viçosa.

GITELSON, A. A.; GRITZ, Y.; MERZLYAK, M. N. Relationships between leaf chlorophyll concentration and spectral reflectance and algorithms for non-destructive chlorophyll assessment in higher plant leaves. Journal of Plant Physiologic, v. 160, p. 27I-282, 2003.

GITELSON, A. A.; KEYDAN, G. P.; MERZLYAK, M. N. Threeband model for noinvasive estimation of chlorophyll carotenoids and anthocyanin concentrations in higher plant leaves. Geophysical Research Letters, v. 33, p. I-5, 2006. 
GITELSON, A. A.; CHIVKUNOVA, O. B.; MERZLYAK, M. N. Nondestructive estimation of anthocyanins and chlorophylls in anthocyanic leaves. American Journal of Botany, v. 96, n. I0, p. $|86|-\mid 868,2009$.

GONG, P.; PU, R.; HEALD, R. C. Analysis of in situ hyperspectral data for nutrient estimation of giant sequoia. International Journal of Remote Sensing, v. 23, n. 9, p. I827-1850, 2002.

HAKALA, M.; TUOMINEN, I.; KERÄNEN, M.; TYYSTJÄRVI, T.; TYYSTJÄRVI, E. Evidence for the role of the oxygenevolving manganese complex in photoinhibition of photosystem II. Biochemical Biophysical Acta, v. I706, p. 68-80, 2005.

HANSEN, P. M., SCHJOERRING, J. K. Reflectance measurement of canopy biomass and nitrogen status in wheat crops using normalized difference vegetation indices and partial least squares regression. Remote Sensing of Environment, v. 86, p. 542-553, 2003.

HORLER, D. N.; DOCKRAY, M.; BARBER, J. The red edge of plant leaf reflectance. International Journal of Remote Sensing, v. 4, p. 273-288, 1983.

KAWAMURA, K.; MACKAY, A. D.; TUOHY, M. P.; BETTERIDGE, K.; SANCHES, I. D.; INOUE, Y. Potential for spectral indices to remotely sense phosphorus and potassium concentration of legume-based pasture as a means of assessing soil phosphorus and potassium fertility status. International Journal of Remote Sensing, v. 32, n. I, p. 103-124, 20II.

MAHAJAN, G. R.; SAHOO, R. N.; PANDEY, R. N.; GUPTA V. K.; KUMAR, D. Using hyperspectral remote sensing techniques to monitor nitrogen, phosphorus, sulphur and potassium in wheat (Triticum aestivum L.). Precision Agriculture, v. 15, n. I, p. 499-522, 2014

MARIOTTI, M.; ERCOLI, L.; MASONI, A. Spectral properties of iron-deficient corn and sunflower leaves. Remote Sensing of Environment, v. 58, p. 282-288, 1996.

MARSCHNER, H. Mineral nutrition of higher plants. Academic Press, 1995. 672 p.

MERZLYAK, M. N.; GITELSON, A. A.; CHIVKUNOVA, O. B.; SOLOVCHENCO, A. E.; POGOSYAN, S. I. Application of reflectance spectroscopy for analysis of higher plant pigments. Russian Journal of Plant Physiology, v. 50, n. 5, p. 704-710, 2003.

MILTON, N. M.; EISWERTH, B. A.; AGER, C. M. Effect of phosphorus deficiency on spectral reflectance and morphology of soybean plants. Remote Sensing of Environment, v. 36, p. |2|-|27, I99|.

MUTANGA, O.; SKIDMORE, A. K.; PRINS, H. H. T. Predicting in situ pasture quality in the Kruger National Park, South Africa, using continuum-removed absorption features. Remote Sensing of Environment, v. 89, p. 393-408, 2004.
OLIVEIRA, L. F. R., OLIVEIRA, M. L. R., GOMES, F. S., SANTANA, R. C. Estimating foliar nitrogen in Eucalyptus using vegetation indexes. Scientia Agricola, v. 74, n. 2, p. |42-|47, 2017.

OLLINGER, S. V. Sources of variability in canopy reflectance and the convergent properties of plants. New Phytology, v. I89, p. $375-394,201$ I.

ÖZYIĞIT, Y.; BILGEN, M. Use of spectral reflectance values for determining nitrogen, phosphorus, and potassium concentrations of rangeland plants. Journal Agricola Science Technology, v. I5, p. I537-I545, 2013.

PIMSTEIN, A.; KARNIELI, A.; SURINDER, K. B.; BONFIL, D. $J$. Exploring remotely sensed technologies for monitoring wheat potassium and phosphorus using field spectroscopy. Field Crops Research, v. I21, p. I25-135, 201 I.

PONZONI, F. J.; GONÇALVES, J. L. M. Spectral features associated with nitrogen, phosphorus, and potassium deficiencies in Eucalyptus saligna seedling leaves. International Journal of Remote Sensing, v. 20, n. I I, p. 2249-2264, 1999.

R CORE TEAM. 20I7. R: A language and environment for statistical computing. R Foundation for Statistical Computing, Vienna, Austria. https: //www.R-project.org./.

RICHARDSON, A. D.; REEVES III, J. B. Quantitative reflectance spectroscopy as an alternative to traditional wet lab analysis of foliar chemistry: near-infrared and mid-infrared calibrations compared. Canadian Journal of Forest Research, v. 35, p. II22-II30, 2005.

SAVITZKY, A.; GOLAY, M. J. E. Smoothing and differentiation of data by simplified least squares procedures. Analytical Chemistry, v. 36, n. 8, p. 1627-1639, 1964.

SAUR, E.; NAMBIAR, E. K. S.; FIFE, D. N. Foliar nutrient retranslocation in Eucalyptus globulus. Tree Physiology, v. 20, n. I6, p. II05-III2, 2000

SCHLEMMER, M.; GITELSON, A.; SCHEPERS, J.; FERGUSON, R.; PENG, Y.; SHANAHAN, J.; RUNDQUIST, D. Remote estimation of nitrogen and chlorophyll concentrations in maize at leaf and canopy levels. International Journal of Applied Earth Observation and Geoinformation, v. 25, p. 47-54, 2013.

SIEGBAHN, P. E. M.; CRABTREE, R. H. Manganese oxyl radical intermediates and $\mathrm{O}-\mathrm{O}$ bond formation in photosynthetic oxygen evolution and a proposed role for the calcium cofactor in photosystem II. Journal of American Chemical Society, v. I2I, n. I, p. II7-127, 1999.

SILVERMAN, B. W. Density estimation for statistics and data analysis. Chapman and Hall, 1986.

STEIN, B. R.; THOMAS, V. A.; LORENTZ, L. J.; STRAHM, B. D. Predicting macronutrient concentrations from loblolly pine leaf reflectance across local and regional scales. GIScience \&. Remote Sensing, v. 5I, p. 269-287, 2014.

STROPPIANA, D.; BOSCHETTI, M.; BRIVIO, P. A.; BOCCHI, $S$. Plant nitrogen concentration in paddy rice from field canopy hyperspectral radiometry. Field Crops Research, v. III, p. I I9-129, 2009. 
USTIN, S. L.; GITELSON, A. A.; JACQUEMOUD, S. SCHAEPMAN, M.; ASNER, G. P.; GAMON, J. A.; ZARCOTEJADA, P. Retrieval of foliar information about plant pigment systems from high resolution spectroscopy. Remote Sensing of Environment, v. I I3, p. 567-577, 2009.
WANG, J.; WANG, T.; SHI, T.; WU, G.; SKIDMORE, A. K. A wavelet-based area parameter for indirectly estimating copper concentration in Carex leaves from canopy reflectance. Remote Sensing, v. 7, p. 1534015360, 2015. 